\title{
Effects of Cordyceps militaris on the growth of rumen microorganisms and in vitro rumen fermentation with respect to methane emissions
}

\author{
W. Y. Kim, ${ }^{*}$ M. D. Hanigan,† S. J. Lee,‡ S. M. Lee,§ D. H. Kim,§ J. H. Hyun,ł J. M. Yeo, ${ }^{*}$ and S. S. Lee ${ }^{1}$ \\ ${ }^{*}$ Department of Beef and Dairy Science, Korea National College of Agriculture and Fisheries, Hwaseong, 445-893, Korea \\ †Virginia Polytechnic Institute and State University, Blacksburg 24061 \\ łDivision of Applied Life Science (BK21), Graduate School of Gyeongsang National University, IALS, Jinju, 660-701, Korea, \\ §National Institute of Animal Science, Rural Development Association, Suwon, 441-706 Korea
}

\section{ABSTRACT}

This experiment was designed to investigate the effects of different concentrations $(0.00,0.10,0.15,0.20$, 0.25 , and $0.30 \mathrm{~g} / \mathrm{L}$ ) of dried Cordyceps militaris mushroom on in vitro anaerobic ruminal microbe fermentation and methane production using soluble starch as a substrate. Ruminal fluids were collected from Korean native cattle, mixed with phosphate buffer (1:2), and incubated anaerobically at $38^{\circ} \mathrm{C}$ for $3,6,9,12$, 24, 36, 48, and $72 \mathrm{~h}$. The addition of C. militaris significantly increased total volatile fatty acid and total gas production. The molar proportion of acetate was decreased and that of propionate was increased, with a corresponding decrease in the acetate:propionate ratio. As the concentration of C. militaris increased from 0.10 to $0.30 \mathrm{~g} / \mathrm{L}$, methane and hydrogen production decreased. The decrease in methane accumulation relative to the control was 14.1, 22.0, 24.9, 39.7, and $40.9 \%$ for the $0.10,0.15,0.20,0.25$, and $0.30 \mathrm{~g} / \mathrm{L}$ treatments, respectively. Ammonia-N concentration and numbers of live protozoa decreased linearly with increasing concentrations of C. militaris. The $\mathrm{pH}$ of the medium significantly decreased at the highest level of $C$. militaris compared with the control. In conclusion, C. militaris stimulated mixed ruminal microorganism fermentation and inhibited methane production in vitro. Therefore, C. militaris could be developed as a novel compound for antimethanogenesis.

Key words: Cordyceps militaris, methane, protozoa, rumen fermentation

\section{INTRODUCTION}

Methane $\left(\mathrm{CH}_{4}\right)$ produced as a result of digestible structural carbohydrate fermentation in the rumen represents 7 to $10 \%$ feed energy loss to the host ani-

Received February 18, 2014.

Accepted August 7, 2014.

${ }^{1}$ Corresponding author: lss@gnu.ac.kr mal (Takahashi et al., 1997; Takahashi, 2001) and has received attention as a potential contributor to global warming (Leng, 1991; Moss, 1993). Because methane production is negatively correlated with energy utilization in ruminants (Ørskov et al., 1968), many compounds have been tested in vitro and in vivo as methane inhibitors (Czerkawski and Breckenridge, 1972; Martin and Macy, 1985). Methanogenic archaea were metabolically correlated with ciliate protozoa (Stumm et al., 1982; Newbold et al., 1995), and elimination of ciliate protozoa from the rumen reduced methane emissions by 30 to $45 \%$ (Jouany et al., 1981; Itabashi et al., 1984; Ushida et al., 1986). Several compounds have the potential to reduce methane production from ruminants although their long-term effects have not been well established. Some compounds are toxic or may not be economically feasible (Hristov et al., 2013), or an adaptive response may occur in some bioactive compounds after supplementation (Wallace et al., 2002).

Cordyceps militaris, a traditional Chinese medicinal mushroom, is an entomogenous fungus belonging to the Ascomycotina. The mushroom is traditionally called "DongChung HaCho" in Korea meaning "summer-plant and winter-worm." During the past several decades, many kinds of bioactive constituents from Cordyceps spp. have been isolated and characterized. These include cordycepic acid (D-mannitol), cordycepin, ophicordin, polysaccharides, amino acids, galactosaminoglycan, nucleic acids, steroids, and L-tryptophan (Tang and Eisenbrand, 1992; Namba, 1993; Huang et al., 2003). In addition, $C$. militaris showed several therapeutic effects, including immunoregulative (Zhu et al., 1998a,b; Ahn et al., 2000; Zhou et al., 2002), anticancer (Müller et al., 1977), antibacterial (Ahn et al., 2000), antifungal (Sugar and McCaffrey, 1998), larvicidal (Kim et al., 2002), and antioxidant (Li et al., 2001; Tsai et al., 2001) effects. Cordyceps militaris mycelia have been shown to alter in vitro rumen microbial fermentation with increased production of gas and VFA, cellulose digestion, and cellulolytic enzyme activities (Yeo et al., 2009, 2011). But no information exists with respect 
to $C$. militaris modulating methane production in the rumen. Therefore, the present study was conducted to observe the effects of $C$. militaris on ruminal microorganism fermentation with particular reference to methane production in vitro.

\section{MATERIALS AND METHODS}

\section{Sample Preparation}

Because Cordyceps are very difficult to collect due to their very small size and restricted area of growth, mass production of these fungi has been established through artificial cultivation. Dried C. militaris was cultured on floral medium composed of gluten, soybean protein, beer yeast, and corn steep liquor (culturing method and medium composition were patented in Korea, patent registration No.1006442430000; Lee, 2006) obtained from EuGene Bio Farm (Hwaseong City, Gyeonggi Province, Korea). The manufacturer reported that $C$. militaris mycelia used in the present study contained about 2.3 times more cordycepin $(1.6 \mathrm{mg} / \mathrm{g}$ of $\mathrm{DM})$ than C. militaris traditionally cultured on faunal pupae $(0.7 \mathrm{mg} / \mathrm{g}$ of DM). It contained $8.6 \%$ moisture, $76.2 \%$ CP, $12.2 \%$ crude fiber, $1.0 \%$ ether extract, $3.2 \%$ crude ash, and $7.4 \%$ nitrogen-free extract.

\section{In Vitro Batch Fermentation}

The anaerobic culture techniques of Hungate (1950) with modifications (Bryant and Burkey, 1953; Bryant, 1972) were carried out for all incubations and the experimental procedures were the same as those described in a previous study (Yeo et al., 2009) except that 200 mg of soluble potato starch (S2004; Sigma-Aldrich Korea, Yongin City, Gyeonggi-do, Korea) was used as a carbon source.

Dried C. militaris was added gravimetrically to achieve final concentrations of $0.00,0.10,0.15,0.20$, 0.25 , and $0.30 \mathrm{~g} / \mathrm{L}$. The bottles (3 replicates per treatment) were closed with butyl rubber stoppers under the Hungate anaerobic gassing system hooked to a source of oxygen-free gas, sealed with aluminum caps, and placed in an incubator at $38^{\circ} \mathrm{C}$ for $3,6,9,12,24,36$, 48 , and $72 \mathrm{~h}$ without shaking. The experimental design was a complete randomized design with 3 replications per treatment.

\section{Total, Hydrogen, and Methane Gas Production}

At the end of each incubation time, a needle attached to a glass syringe was inserted through the butyl rubber stopper, and the volume of gas exceeding $1 \mathrm{~atm}$ was measured through displacement of the syringe plunger using the technique of Fedorak and Hrwdey (1983) with modifications (Callaway and Martin, 1996). A 0.5-mL subsample of gas was analyzed for hydrogen and methane content by GC (model CP-3800, Varian Inc., Palo Alto, CA) using a molecular sieve $13 \times, 45$ - to 60 -mesh column $(2.0 \mathrm{~mm} \times 3.2 \mathrm{~mm} \times 2.0 \mathrm{~mm}$, stainless steel $)$ and a thermal conductivity detector (oven temperature $=60^{\circ} \mathrm{C}$, injector and thermal conductivity detector temperature $=120^{\circ} \mathrm{C}$, flame-ionization detector temperature $\left.=200^{\circ} \mathrm{C}\right)$. The carrier gas $\left(\mathrm{N}_{2}\right)$ flow rate was $50 \mathrm{~mL} / \mathrm{min}$.

\section{$\mathrm{pH}, \mathrm{NH}_{3}-\mathrm{N}$, and VFA}

After determination of gas production, the bottles were uncapped, and $\mathrm{pH}$ of the culture fluid was determined using a pH meter (MP 230, Mettler-Toledo, Greifensee, Switzerland). For analysis of ammonia-N and VFA, $1 \mathrm{~mL}$ of $25 \%$ meta-phosphoric acid was added to $5 \mathrm{~mL}$ of fermentation fluid and centrifuged $(10,000 \times \mathrm{g}$ for 10 min at $4^{\circ} \mathrm{C}$ ); supernatants were stored at $-30^{\circ} \mathrm{C}$ until analysis. Volatile fatty acids were analyzed by GC (model GC-14B, Shimadzu Co. Ltd., Tokyo, Japan) using a Thermon-3000 5\% Shincarbon A column $(1.6 \mathrm{~m} \times$ $3.2 \mathrm{~mm}$ i.d., 60 to 80 mesh, Shinwakako, Kyoto, Japan) and flame-ionization detector (column temperature = $130^{\circ} \mathrm{C}$, injector and detector temperature $=200^{\circ} \mathrm{C}$ ). The carrier gas $\left(\mathrm{N}_{2}\right)$ flow rate was $50 \mathrm{~mL} / \mathrm{min}$. The micro-diffusion method was used to determine $\mathrm{NH}_{3}-\mathrm{N}$ (Conway, 1962).

\section{Microbial Populations}

Total viable bacteria and fungi in the culture fluid were enumerated by the method of Holdeman et al. (1977) and Joblin (1981) using anaerobic roll tubes. Samples were fixed in methylgreen-formalin-saline (MFS) solution consisting of $900 \mathrm{~mL}$ of distilled water, $100 \mathrm{~mL}$ of $35 \%$ formaldehyde solution, $0.6 \mathrm{~g}$ of methylgreen, and $8.0 \mathrm{~g}$ of $\mathrm{NaCl}$ before enumeration of rumen protozoa by the method of Ogimoto and Imai (1981). Protozoa fixed in MFS were diluted in the same solution and counted under a microscope with a planktoncounting glass (cat. no. 900, Hausser Scientific, Blue Bell, PA).

\section{Relative Quantification of Specific Ruminal Microbes}

Total nucleic acid was extracted from the incubated rumen samples using the modified bead-beating protocol (Yu and Morrison, 2004) with the QIAamp DNA mini kit (Qiagen, Valencia, CA). This was ac- 
complished by taking a $1.0-\mathrm{mL}$ aliquot from the culture medium using a wide-bore pipette to ensure collection of a homogeneous sample. Nucleic acid concentrations were measured using a NanoDrop Spectrophotometer (Thermo Scientific, Wilmington, DE).

Quantitative (q)PCR assays for enumeration of methanogenic archaea, ciliate protozoa, and cellulolytic bacterial species (Fibrobacter succinogenes, Ruminococcus flavefaciens, Ruminococcus albus) were performed according to the methods described by Koike and Kobayashi (2001), Denman and McSweeney (2006), and Denman et al. (2007) on a real-time PCR machine (CFX96 Real-Time system, Bio-Rad, Hercules, CA) using the SYBR Green Supermix (QPK-201, Toyobo Co. Ltd., Tokyo, Japan). The PCR primer sets used are shown in Table 1. They included group-specific primers for total bacteria as reference genes and species-specific primers for $F$. succinogenes, $R$. flavefaciens, R. albus, methanogenic archaea, and ciliate protozoa. All microbial data were analyzed for calculating relative expressions to total bacteria (Denman and McSweeney, 2005). The values of cycle threshold $(\mathbf{C t})$ after real-time PCR were used to determine the fold change of different microbial populations relative to control (Yuan et al., 2006). Abundance of these microbes was expressed by the equation relative quantification $=2^{-[\Delta \mathrm{Ct} \text { (Target) }-\Delta \mathrm{C} t}$ (Control)], where Ct represents threshold cycle. All qPCR reaction mixtures (final volume of $25 \mu \mathrm{L}$ ) contained forward and reverse primers (10 pmol each), the iQ SYBR Green Supermix (Toyobo Co. Ltd.), and DNA template ranging from 10 to $100 \mathrm{ng}$. A negative control without template DNA was used in every $\mathrm{qPCR}$ assay for each primer. The PCR amplification of the target DNA was conducted following the references in Table 1.

\section{Computation of Data and Statistical Analysis}

To give a more precise estimate of gas production throughout fermentation, the following calculation was used to analyze the kinetic data, as described by Ørskov and McDonald (1979):

$$
\mathrm{G}_{\mathrm{P}}=a+b\left(1-\exp ^{-c \times \text { time }}\right),
$$

where $\mathrm{G}_{\mathrm{P}}$ is gas production ( $\mathrm{mL} / 0.1 \mathrm{~g}$ DM of substrate) at time $\mathrm{t} ; a, b$, and $c$ are the scaling factor for $Y$-axis intercept $(\mathrm{mL} / 0.1 \mathrm{~g}$ of $\mathrm{DM})$, potential gas production $(\mathrm{mL} / 0.1 \mathrm{~g}$ of $\mathrm{DM})$, and the rate constant for gas production per hour $\left(\mathrm{h}^{-1}\right)$, respectively. Gas production rate was fitted to the model by using the nonlinear (NLIN) procedure (SAS Institute, 2011) using Marquardt's algorithm while varying $a, b$, and $c$. Effective gas production $\left(\mathrm{EG}_{\mathrm{P}}\right.$ : substrate availability) from the culture was estimated as $\mathrm{EG}_{\mathrm{P}}=a+b\left[c_{d} /\left(c_{d}+c_{p}\right)\right]$, where $c_{d}$ is a gas production rate constant, and $c_{p}$ is a passage rate constant assumed to be $0.05 / \mathrm{h}$ (NRC, 1989).

Data obtained from the experiment were analyzed using the SAS/OR (SAS Institute, 2011) software package and differences were tested by Duncan's multiple range test. Significance was declared at $P<0.05$.

\section{RESULTS}

Table 2 shows the effects of $C$. militaris on cumulative gas production and its parameters at different incubation times. Gas production was linearly increased by the addition of $C$. militaris at all incubation times. The potential gas production $(a+b)$ was significantly higher for $C$. militaris treatments than for the control treatment. In all treatments, cumulative gas production by mixed rumen microorganisms rapidly increased from 3 to $12 \mathrm{~h}$ of incubation. The addition of $C$. militaris significantly increased $(P<0.05)$ total gas production compared with the control except at 6,9 , and $24 \mathrm{~h}$ of incubation for 0.10 and $0.15 \mathrm{~g} / \mathrm{L}$ treatments. The highest total gas production was seen

Table 1. Primers $(F=$ forward; $R=$ reverse) for real-time PCR assay

\begin{tabular}{llll}
\hline Target species & Primer sequence $\left(5^{\prime} \rightarrow 3^{\prime}\right)$ & $\begin{array}{l}\text { Size } \\
(\mathrm{bp})\end{array}$ & Reference \\
\hline Total bacteria & F: CGG CAA CGA GCG CAA CCC & 130 & Denman and McSweeney (2006) \\
Ruminococcus albus & R: CCA TTG TAG CAC GTG TGT AGC C & 175 & Koike and Kobayashi (2001) \\
Ruminococcus flavefaciens & F: CCC TAA AAG CAG TCT TAG TTC G & 132 & Denman and McSweeney (2006) \\
Fibrobacter succinogenes & F: CCT CCT TGC GGT TAG AAC A & \multirow{2}{*}{ Denman and McSweeney (2006) } \\
Methanogenic archaea & R: CGG TCT CTG TAT GTT ATG AGG TAT TAC C & \multirow{2}{*}{ Denman et al. (2007) } \\
Ciliate protozoa & R: CGC CTG CCC CTG AAC TAT C & 140 & Skillman et al. (2006) \\
& F: TTC GGT GGA TCD CAR AGR GC & 180 & \\
\hline
\end{tabular}




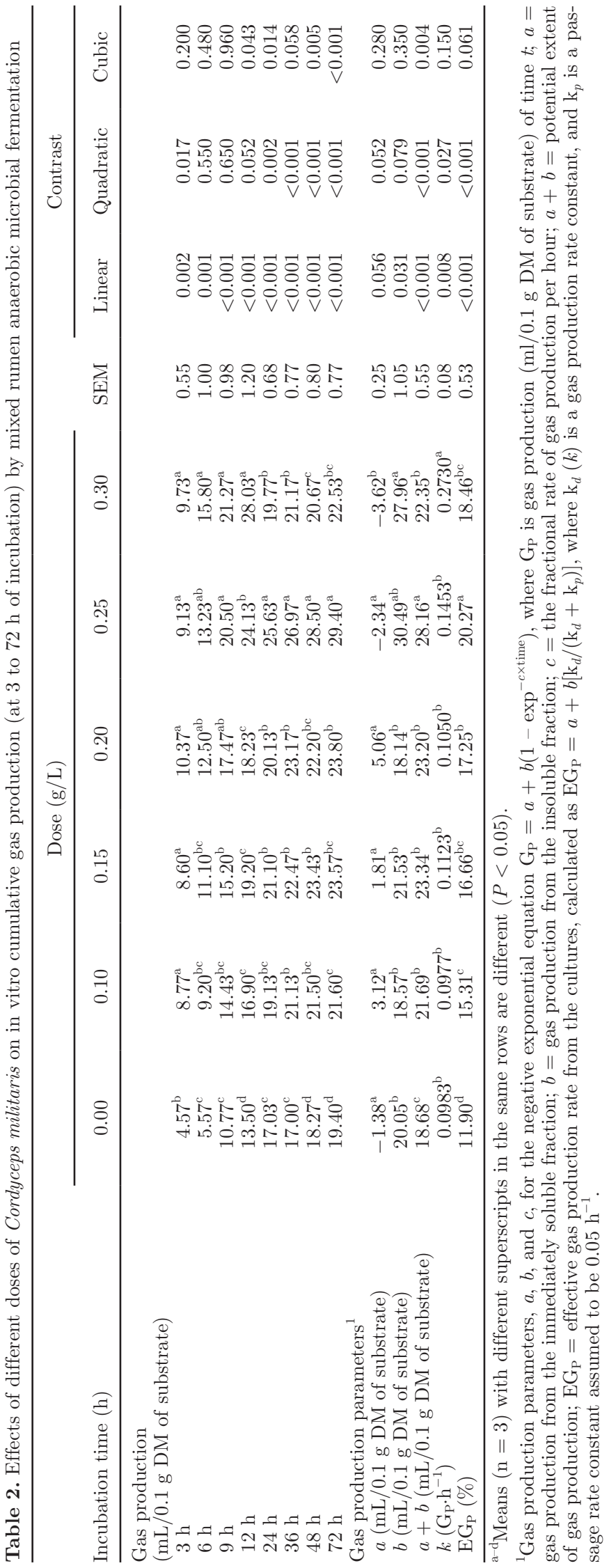

$(P<0.05)$ in the $0.25 \mathrm{~g} / \mathrm{L}$ treatment from 24 to $72 \mathrm{~h}$ of incubation.

Table 3 shows the effects of $C$. militaris on methane and hydrogen gas production. The addition of $C$. militaris reduced methane production linearly $(P<0.05)$ from 24 to $72 \mathrm{~h}$, but a linear reduction of hydrogen gas production was seen only at $24 \mathrm{~h}$ of incubation. The largest reduction of methane production relative to the control was seen at $24 \mathrm{~h}$ of incubation, showing reductions of $14.1,22.0,24.9,39.7$, and $40.9 \%$ for 0.10 , $0.15,0.20,0.25$, and $0.30 \mathrm{~g} / \mathrm{L}$ treatments, respectively.

A linear reduction of the concentration of ammonia$\mathrm{N}$ by the addition of $C$. militaris was seen at 12 and $24 \mathrm{~h}$ of incubation (Table 4). Total VFA concentration was linearly increased $(P<0.05)$ by the addition of $C$. militaris from 24 to $72 \mathrm{~h}$ (Table 4), and corresponding decreases of $\mathrm{pH}$ were seen. At all levels of $C$. militaris addition at $24 \mathrm{~h}$ of incubation (Figure 1), the molar proportion of acetate was decreased $(P<0.05)$ compared with the control and that of propionate was increased $(P<0.05)$ in the 0.20 to $0.30 \mathrm{~g} / \mathrm{L}$ treatments. This led to corresponding decreases in acetate:propionate ratio as the addition of $C$. militaris increased.

Figure 2 shows the effects of $C$. militaris on microbial populations in culture fluid after $24 \mathrm{~h}$ of incubation. The numbers of total and cellulolytic bacteria in the supernatant significantly increased $(P<0.05)$ at the highest dose level of $C$. militaris compared with the control. Significant decreases $(P<0.05)$ in the number of live protozoa and anaerobic fungi were seen in the 0.25 and $0.30 \mathrm{~g} / \mathrm{L}$ treatments compared with the control, whereas numbers of dead protozoa remained similar between the treatments.

Real-time PCR analysis indicated that C. militaris significantly affected abundance of cellulolytic bacteria (R. albus, R. flavefaciens, and F. succinogenes), ciliate protozoa, and methanogenic archaea (Figure 3 ). The addition of $C$. militaris significantly decreased $(P<$ 0.05 ) the abundance of $R$. albus in the 0.25 and 0.30 $\mathrm{g} / \mathrm{L}$ treatments at 24 and $48 \mathrm{~h}$ of incubation, and for the $0.10,0.20$, and $0.30 \mathrm{~g} / \mathrm{L}$ treatments at $12 \mathrm{~h}$ of incubation. Supplementation with $C$. militaris also decreased the abundance of $F$. succinogenes at $24 \mathrm{~h}$ except in the 0.15 and $0.20 \mathrm{~g} / \mathrm{L}$ treatments but decreased responses were not shown at 12 and $48 \mathrm{~h}$ of incubation. On the other hand, $R$. flavefaciens in the $0.15,0.25$, and 0.30 $\mathrm{g} / \mathrm{L}$ treatments was significantly increased $(P<0.05)$ at $24 \mathrm{~h}$ of incubation, and increased responses were shown for the 0.10 and $0.15 \mathrm{~g} / \mathrm{L}$ treatments only at 12 and $48 \mathrm{~h}$ of incubation, respectively. A significant decrease $(P<0.05)$ in the abundance of ciliate protozoa was evident at $24 \mathrm{~h}$ of incubation when $C$. militaris was added at a level greater than $0.15 \mathrm{~g} / \mathrm{L}$. At $48 \mathrm{~h}$ of incubation, reductions in the abundance of ciliate protozoa 
Table 3. Effects of different doses of Cordyceps militaris on methane $\left(\mathrm{CH}_{4}\right)$ and hydrogen $\left(\mathrm{H}_{2}\right)$ gas production (at 3 to $72 \mathrm{~h}$ of incubation) in supernatant of growing mixed rumen anaerobic microorganisms

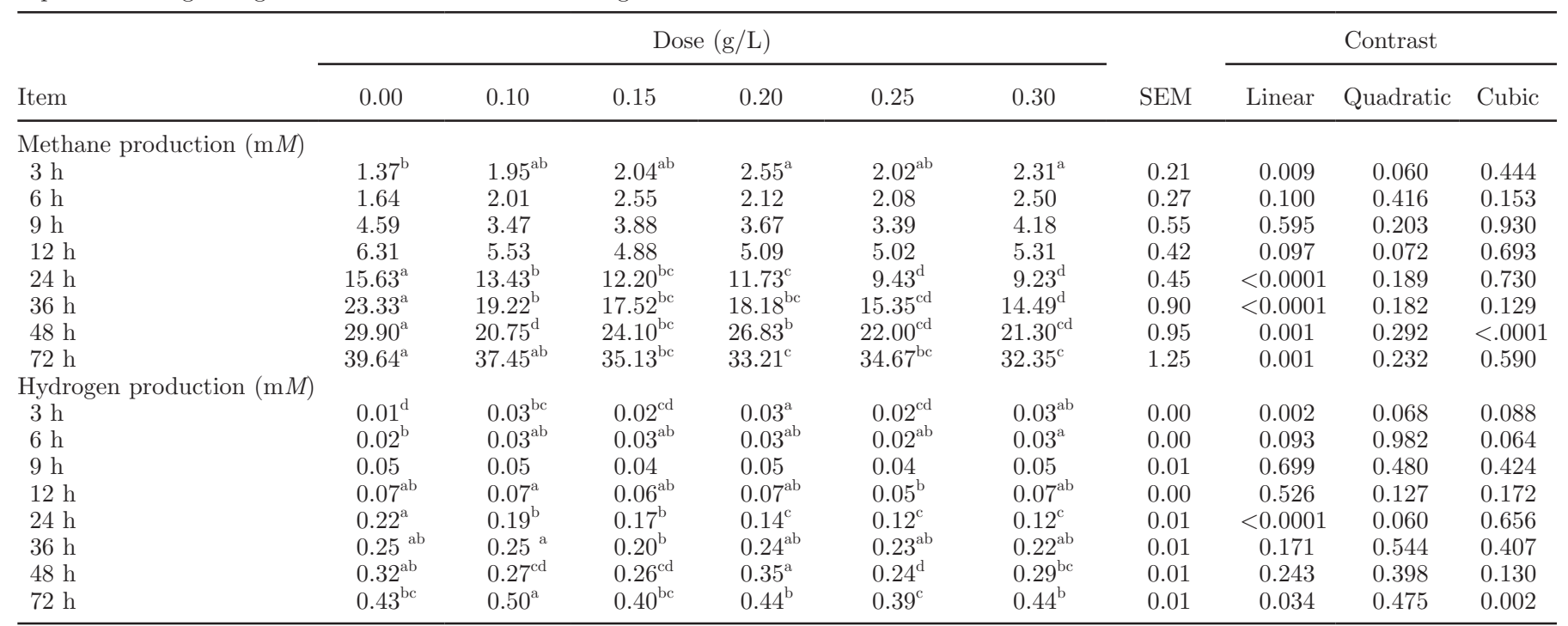

${ }^{\mathrm{a}-\mathrm{d}}$ Means $(\mathrm{n}=3)$ with different superscripts in the same rows are different $(P<0.05)$.

were seen only in the 0.25 and $0.30 \mathrm{~g} / \mathrm{L}$ treatments. $0.30 \mathrm{~g} / \mathrm{L}$ treatments at $12 \mathrm{~h}$ and the $0.25 \mathrm{~g} / \mathrm{L}$ treatThe effects of $C$. militaris addition on the abundance of ment at $24 \mathrm{~h}$ of incubation decreased the abundance of methanogenic archaea were inconsistent. The 0.10 and methanogenic archaea; however, at $48 \mathrm{~h}$ of incubation,

Table 4. Effects of different doses of Cordyceps militaris on $\mathrm{pH}$ value, ammonia-N, and total VFA production (at 3 to $72 \mathrm{~h}$ of incubation) in supernatant of growing mixed rumen anaerobic microorganisms

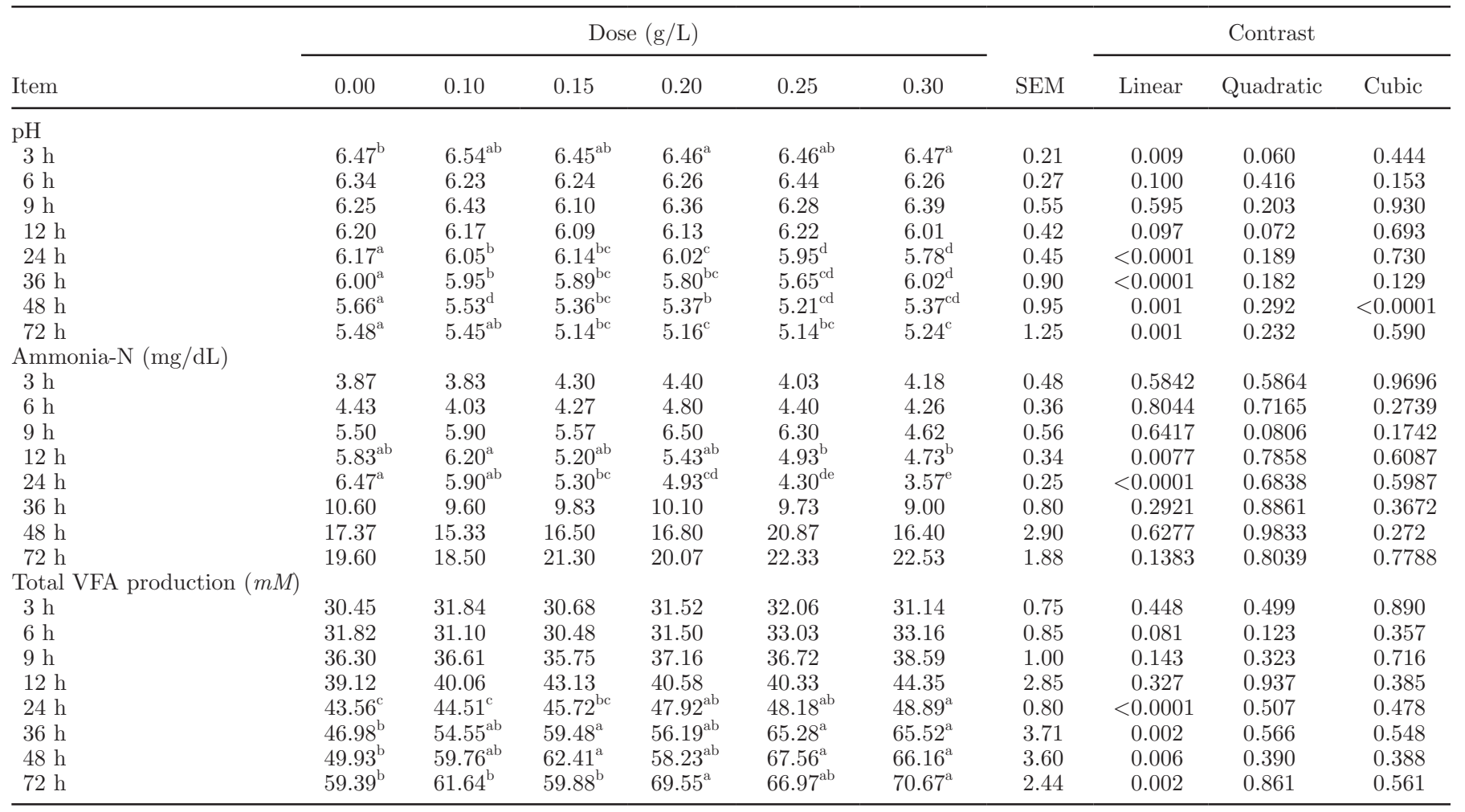

\footnotetext{
${ }^{\mathrm{a}-\mathrm{e}}$ Means $(\mathrm{n}=3)$ with different superscripts in the same rows are different $(P<0.05)$.
} 


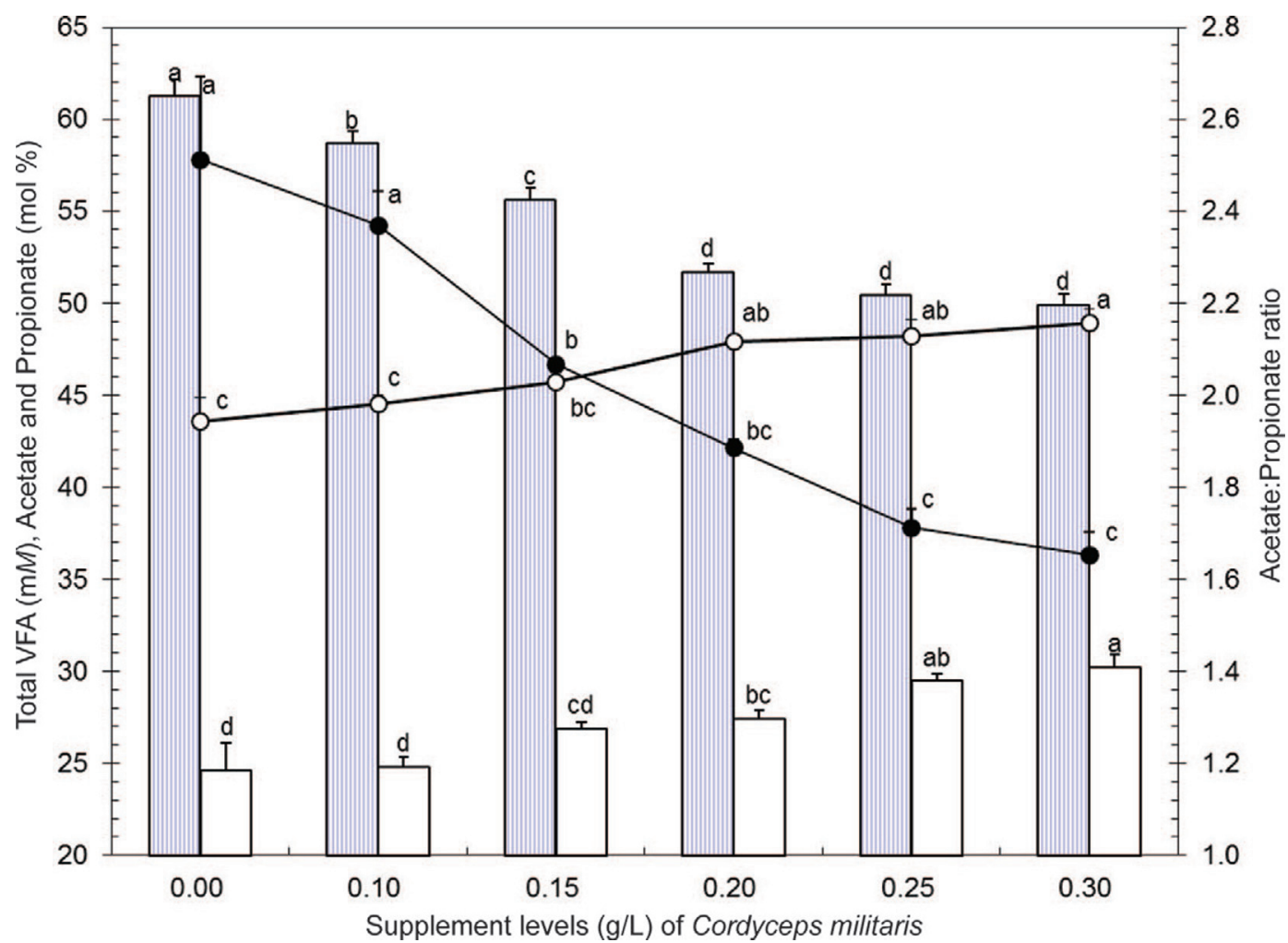

Figure 1. Influence of different doses of Cordyceps militaris on total VFA (O), and the molar proportion (\%) of acetate (shaded bars), propionate (open bars), and acetate:propionate ratio (A:P ratio, $\bullet$ ) in supernatant of growing mixed rumen anaerobic microorganisms after a 24-h incubation. Lowercase letters indicate statistical significance; means $(\mathrm{n}=3)$ with different letters are significantly different $(P<0.05)$. Color version available in the online PDF.

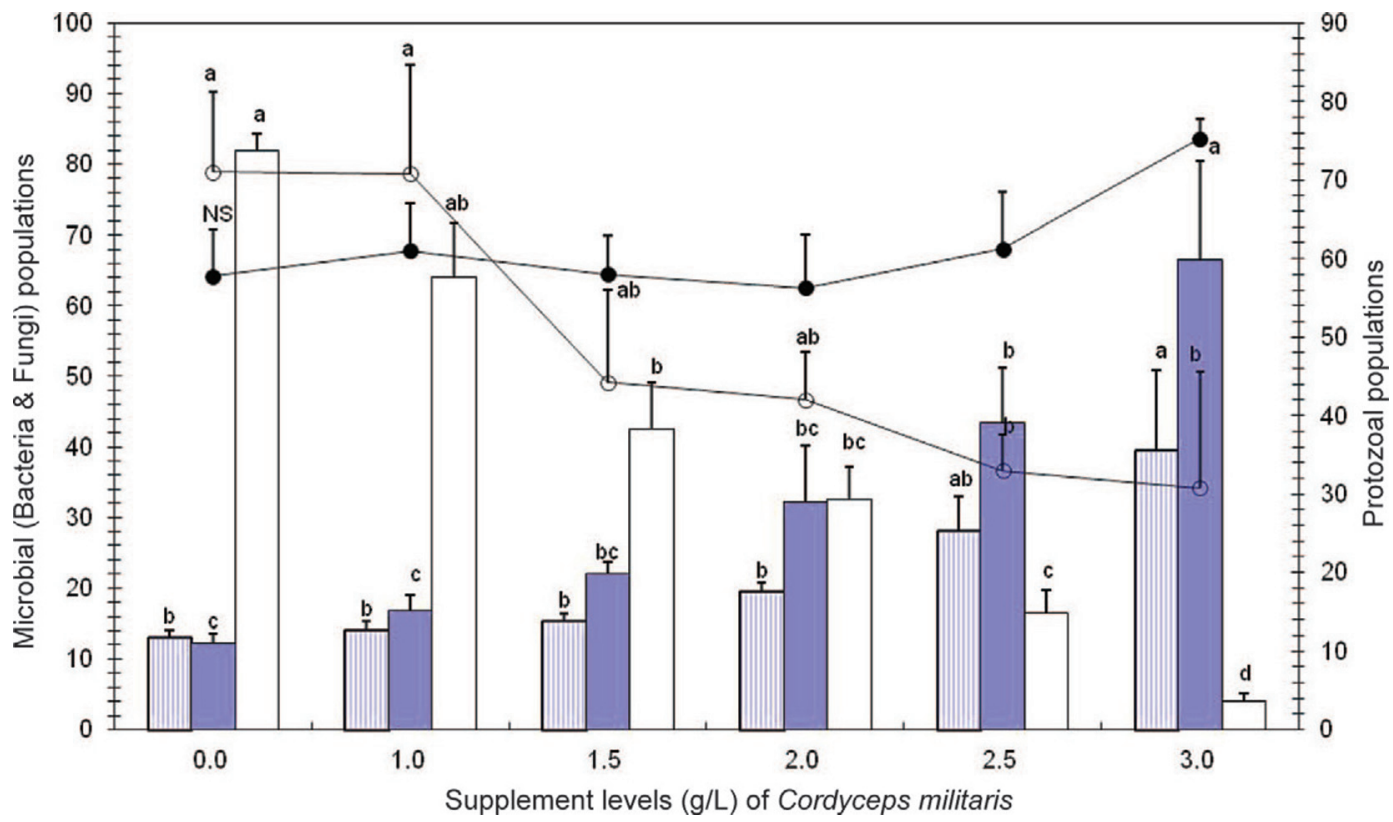

Figure 2. Influence of different doses of Cordyceps militaris on the populations of total bacteria $\left(\times 10^{9}\right.$ cfu $/ \mathrm{mL}$, shaded bars $)$, cellulolytic bacteria $\left(\times 10^{6} \mathrm{cfu} / \mathrm{mL}\right.$, solid bars $)$, anaerobic fungi $\left(\times 10^{3} \mathrm{cfu} / \mathrm{mL}\right.$, open bars $)$, live protozoa $\left(\times 10^{2} \mathrm{cfu} / \mathrm{mL}, \bigcirc\right)$, and dead protozoa $\left(\times 10^{3} \mathrm{cfu} / \mathrm{mL}\right.$, -) in supernatant of growing mixed rumen anaerobic microorganisms after a 24-h incubation. Lowercase letters indicate statistical significance; means $(\mathrm{n}=3)$ with different letters are significantly different $(P<0.05)$. Color version available in the online PDF 

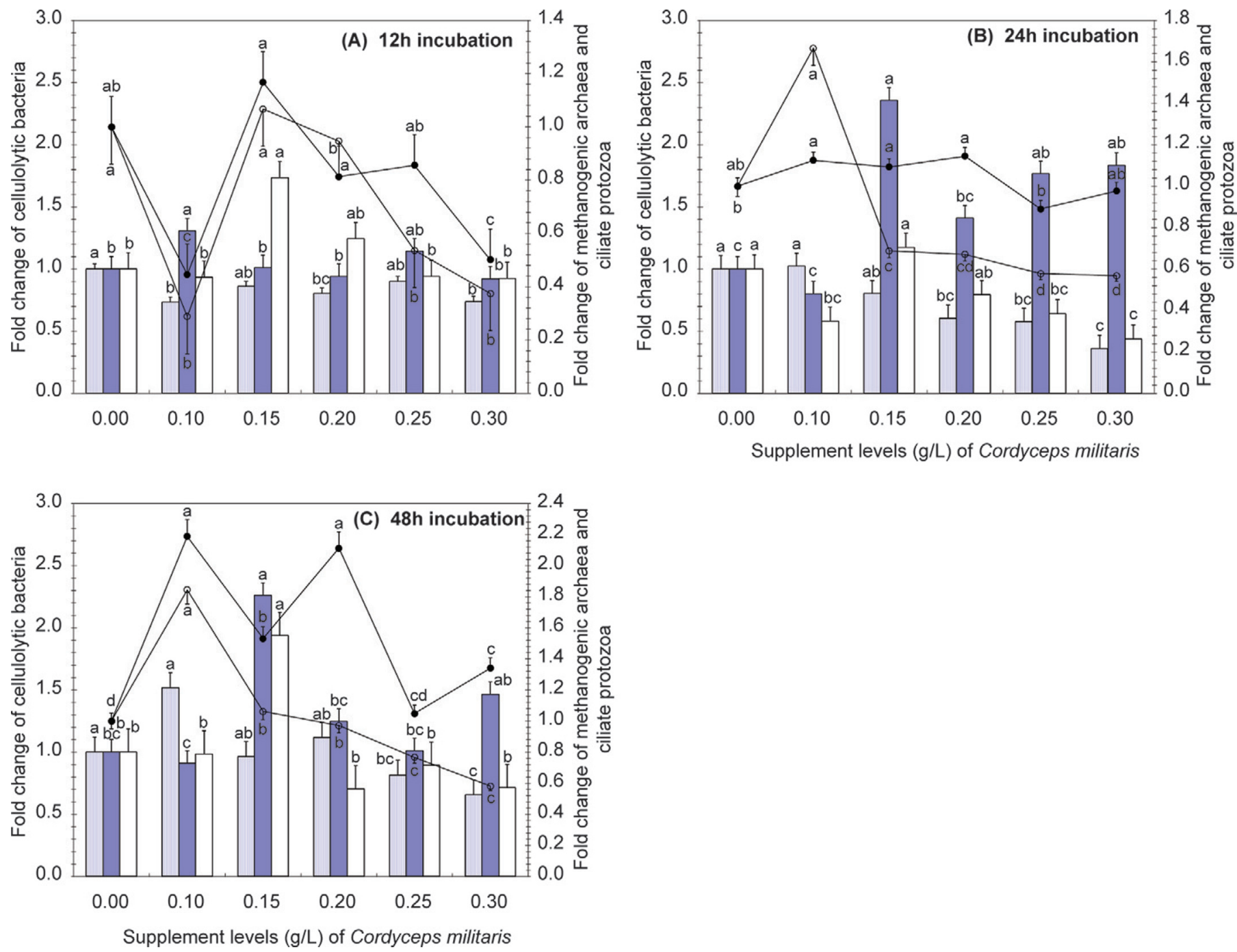

Figure 3. Influence of different doses of Cordyceps militaris on the relative quantification analysis of methanogenic archaea (•), ciliate protozoa ( $\bigcirc$ ), and cellulolytic bacteria: Ruminococcus albus (shaded bars), Ruminococcus flavefaciens (solid bars), and Fibrobacter succinogenes (open bars) in supernatant of growing mixed rumen anaerobic microorganisms after (A) 12-h, (B) 24-h, and (C) 48-h incubations. Lowercase letters indicate statistical significance; means $(\mathrm{n}=3)$ with different letters are significantly different $(P<0.05)$. Color version available in the online PDF.

addition of $C$. militaris, except at the $0.25 \mathrm{~g} / \mathrm{L}$ level, increased the abundance of methanogenic archaea.

\section{DISCUSSION}

In general, in vitro ruminal anaerobic microbial fermentation was strongly affected by the addition of dried C. militaris. The addition of C. militaris increased cumulative and potential gas production, but reduced production of methane and hydrogen gas. Supplementation with $C$. militaris appeared to accelerate the fermentation process, especially in the early stages of incubation, as shown by accelerated rates of cumulative gas production (Table 2). Total gas production was closely related to the digestion of fermentation substrates, VFA production, and microbial activity and growth (Getachew et al., 2004). In the present study, although we observed a lag time between gas production and the responses of $\mathrm{pH}$ and total VFA production, a positive correlation between gas production and total VFA production was found $\left(\mathrm{R}^{2}=\right.$ $0.63, P<0.001)$. The increases in total gas production in response to the addition of $C$. militaris, which is highly nutritious, might be due to the increased activ- 
ity of related microbes. It is true that the control vials contained less nutrients ( $\mathrm{N}$ and carbohydrates) than did the treatment vials, but the supply of $\mathrm{N}$ in the control vials would seem unlikely to be limited during the early incubation periods, as shown by the similar ammonia- $\mathrm{N}$ concentrations between treatments (Table 4). Furthermore, ammonia- $\mathrm{N}$ concentration at 12 and $24 \mathrm{~h}$ was lower for the treatments than for the control. The difference in supply of carbohydrates would likely be minimal because of the high level of $\mathrm{CP}(76 \%)$ in C. militaris. This suggests that stimulatory responses to $C$. militaris might have been from an adverse effect on protozoan population and a positive effect on bacterial population rather than from differences in the supply of major nutrients. The numbers of total and cellulolytic bacteria were increased by the addition of C. militaris (Figure 2).

Methane produced by enteric fermentation in ruminants not only represents a severe loss of feed energy for the animals but also has an ecological impact. Therefore, reducing methane production could have significant economic and environmental benefits. In the present study, addition of C. militaris decreased methane production linearly from 24 to $72 \mathrm{~h}$ of incubation with a maximum reduction of $40.9 \%$ observed for the highest level of $C$. militaris at $24 \mathrm{~h}$ of incubation (Table 3). Kamra et al. (2008) screened 93 plant extracts for their potential to inhibit in vitro methanogenesis and ciliate protozoa using buffalo rumen liquor, and reported that 20 extracts abated methane production by more than $25 \%$, accompanied by a sharp decline in methanogen numbers. Some plant species showing a more pronounced effect are rich in saponins (Sapindus mukorossi), tannins (Terminalia chebula, Populus deltoids, Mangifera indica, and Psidium guajava), or essential oils (Syzygium aromaticum and Allium sativum). In the RUMEN-UP project (Rumen Metabolism Enhanced Naturally Using Plants; http://www.rowett. ac.uk/rumen_up/index.html), potential candidates were selected from 500 different plant species based on their ability to inhibit methane production by 15 to $27 \%$ without a detrimental effect on total VFA production or feed digestibility. The plant species selected were the Italian plumeless thistle (Carduus pycnocephalus, $30 \%$ inhibition), the Chinese peony (Paeonia lactiflora, 8-53\%), the European aspen (Populus tremula, 25\%), the sweet cherry (Prunus avium, 20\%), goat willow (Salix caprea, 30\%), English oak (Quercus pedunculata, $25 \%$ ), and Sikkim rhubarb (Rheum nobile, 25\%). The application of these candidate species to ruminant livestock is still in the early stage and many points still need to be clarified (Kobayashi, 2010).
Our findings cannot be directly compared with numerous methane-suppressing agents reported in the literature because this is the first study to show that C. militaris can suppress methane emission. However, the modes of action of C. militaris appear similar to those of monensin and secondary plant metabolites (saponins) because the reduction of methane production in response to the addition of $C$. militaris was accompanied by a decrease in live protozoan population (Figure 2) and abundance of ciliate protozoa (Figure 3 ). It has been reported that monensin and saponin affect methanogens indirectly by suppressing ciliate protozoa (Hino et al., 1993; Lila et al., 2003). Rumen ciliate are known to provide hydrogen as a substrate for methanogens (Stumm and Zwart, 1986; Ushida et al., 1997), and methanogenic archaea are metabolically correlated with ciliate protozoa (Stumm et al., 1982; Newbold et al., 1995). Therefore, elimination of ciliate protozoa from the rumen leads to reduced methane emission (Jouany et al., 1981; Itabashi et al., 1984; Ushida et al., 1986). But it has been reported that the response of methane production to saponin in in vitro could be affected by saponin source and dose level (Hess et al., 2003; Beauchemin et al., 2008), and also by the potential adaptation of the rumen microflora and ruminal fiber digestion in vivo (Lu and Jorgensen, 1987; Holtshausen et al., 2009).

In the present study, a substantial reduction in methane production did not result in a corresponding decrease in the abundance of methanogenic archaea (Figure 3), as was observed in the study of Hess et al. (2003). It has been reported that decreases in methanogen populations may not necessarily lead to a reduction in methane production, at least within a short period of time (Zhou et al., 2011). The discrepancy between the production of methane and the dynamics of the methanogen population might be partly attributable to the insensitivity of some ruminal methanogens to $C$. militaris.

In the present study, although the adverse effects of C. militaris on protozoa were similar to those of monensin and saponin, the increase in numbers of cellulolytic bacteria resulting from addition of $C$. militaris (Figure 2 ) was different from increases due to additions of monensin and sarsaponin, in which cellulolytic bacteria numbers were reduced. It has been suggested that the main reason for the methane-suppressing effects of sarsaponin might be the inhibition of $\mathrm{H}_{2}$-producing bacteria such as cellulolytic bacteria (Wang et al., 2000). In the present study, C. militaris increased $R$. flavefaciens, whereas $F$. succinogenes and $R$. albus were decreased (Figure 3). The reasons for the different responses 
within cellulolytic bacteria populations to the addition of $C$. militaris are not clear.

It is also interesting to note that total VFA increased but ammonia- $\mathrm{N}$ concentration decreased as the supplementation level of $C$. militaris increased (Table 4). Volatile fatty acids are the end products of rumen microbial fermentation and represent the main supply of metabolizable energy for ruminants. Therefore, an increase in VFA production would be nutritionally favorable for the animal. In the present study, the addition of $C$. militaris increased total VFA in the culture fluid. Molar proportion of acetate and acetate:propionate ratio decreased $(P<0.05)$ and propionate increased as $C$. militaris increased (Figure 1). Similar results were obtained for monensin (Chen and Wolin, 1979; Newbold et al., 1995) and sarsaponin (Lila et al., 2003), both of which shifted the proportions of VFA toward higher propionate and decreased acetate. The decreased acetate:propionate ratio reflects both the reduced production of methane and the redirection of hydrogen from methane to propionate (Demeyer and Van Nevel, 1975).

Reduced ammonia- $\mathrm{N}$ concentrations in the rumen are typical when protozoa are inhibited (Williams and Coleman, 1991). It has been reported that the ionophores that inhibit gram-positive bacteria and protozoa also decrease deamination (Van Nevel and Demeyer, 1977). Similar to this, in the present study, a linear reduction of the concentration of ammonia- $\mathrm{N}$, coupled with a decreased protozoan population, was seen following addition of $C$. militaris.

\section{CONCLUSIONS}

Dried C. militaris has the ability to partly inhibit methane production in in vitro microbial fermentations. This compound stimulated mixed ruminal microorganism fermentation and a change in fermentation products, and it decreased methane and hydrogen gas production. Further research is necessary to establish the long-term efficacy of $C$. militaris to inhibit methanogenesis and improve animal performance.

\section{ACKNOWLEDGEMENTS}

This research was supported by Bio-industry Technology Development Program of Food \& Rural Affairs in Ministry of Agriculture (Sejong, Korea), and Cooperative Research Program for Agriculture Science \& Technology Development of Rural Development Administration (Jeonju, Korea).

\section{REFERENCES}

Ahn, Y. J., S. J. Park, S. G. Lee, S. C. Shin, and D. H. Choi. 2000. Cordycepin: selective growth inhibitor derived from liquid culture of Cordyceps militaris against Clostridium spp. J. Agric. Food Chem. 48:2744-2748.

Beauchemin, K. A., M. Kreuzer, F. O'Mara, and T. A. McAllister. 2008. Nutritional management for enteric methane abatement: A review. Aust. J. Exp. Agric. 48:21-27.

Bryant, M. P. 1972. Commentary on the Hungate techniques for culture of anaerobic bacteria. Am. J. Clin. Nutr. 25:1324-1328.

Bryant, M. P., and L. A. Burkey. 1953. Cultural methods and some characteristics of some of the more numerous groups of bacteria in the bovine rumen. J. Dairy Sci. 36:205-217.

Callaway, T. R., and S. A. Martin. 1996. Effects of organic acid and monensin treatment on in vitro mixed ruminal microorganism fermentation of cracked corn. J. Anim. Sci. 74:1982-1989.

Chen, M., and M. J. Wolin. 1979. Effect of monensin and lasalocid on the growth of methanogenic and rumen saccharolytic bacteria. Appl. Environ. Microbiol. 38:72-77.

Conway, E. J. 1962. Microdiffusion Analysis and Volumetric Error. 5th ed. Crosby Lockwood, London, UK.

Czerkawski, J. W., and G. Breckenridge. 1972. Fermentation of various glycolytic intermediates and other compounds by rumen microorganisms, with particular reference to methane production. Br. J. Nutr. 27:131-146.

Demeyer, D. I., and C. J. Van Nevel. 1975. Methanogenesis, an integrated part of carbohydrate fermentation and its control. Pages 366-382 in Digestion and Metabolism in the Ruminant. I. W. McDonald and A. C. I. Warner, ed. University of New England Publishing Unit, Armidale, Australia.

Denman, S. E., and C. S. McSweeney. 2005. Quantitative (real-time) PCR. Pages 105-115 in Methods in Gut Microbial Ecology for Ruminants. H. P. S. Makkar and C. S. McSweeney, ed. Springer, Dordrecht, the Netherlands.

Denman, S. E., and C. S. McSweeney. 2006. Development of a realtime PCR assay for monitoring anaerobic fungal and cellulolytic bacterial populations within the rumen. FEMS Microbiol. Ecol. $58: 572-582$.

Denman, S. E., N. W. Tomkins, and C. S. McSweeney. 2007. Quantitation and diversity analysis of ruminal methanogenic populations in response to the antimethanogenic compound bromochloromethane. FEMS Microbiol. Ecol. 62:313-322.

Fedorak, P. M., and S. E. Hrwdey. 1983. A simple apparatus for measuring gas production by methanogenic cultures in serum bottles. Environ. Technol. Lett. 4:425-432.

Getachew, G., P. H. Robinson, E. J. DePeters, and S. J. Taylor. 2004. Relationships between chemical compositions, dry matter degradation and in vitro gas production of several ruminant feeds. Anim. Feed Sci. Technol. 111:57-71.

Hess, H. D., M. Kreuzer, T. E. Díaz, C. E. Lascano, J. E. Carulla, C. R. Soliva, and A. Machmüller. 2003. Saponin rich tropical fruits affect fermentation and methanogenesis in faunated and defaunated rumen fluid. Anim. Feed Sci. Technol. 109:79-94.

Hino, T., K. Takeshi, M. Kanda, and S. Kumazawa. 1993. Effects of aibellin, a novel peptide antibiotic on rumen fermentation in vitro. J. Dairy Sci. 76:2213-2221.

Holdeman, L. V., E. P. Cato, and W. E. C. Moore. 1977. Anaerobe Laboratory Manual. 4th ed. Virginia Polytechnic Institute and State University, Blacksburg.

Holtshausen, L., A. V. Chaves, K. A. Beauchemin, S. M. McGinn, T. A. McAllister, N. E. Odongo, P. R. Cheeke, and C. Benchaar. 2009. Feeding saponin-containing Yucca Schidigera and Quillaja saponaria to decrease enteric methane production in dairy cows. J. Dairy Sci. 92:2809-2821.

Hristov, A. N., J. Oh, J. L. Firkins, J. Dijkstra, E. Kebreab, G. Waghorn, H. P. S. Makkar, A. T. Adesogan, W. Yang, C. Lee, P. J. Gerber, B. Henderson, and J. M. Tricarico. 2013. Special topics: 
Mitigation of methane and nitrous oxide emissions from animal operations: I. A review of enteric methane mitigation options. J. Anim. Sci. 91:5045-5069.

Huang, L. F., Y. Z. Liang, F. Q. Guo, Z. F. Zhou, and B. M. Cheng. 2003. Simultaneous separation and determination of active components in Cordyceps sinensis and Cordyceps militaris by LC/ESIMS. J. Pharm. Biomed. Anal. 33:1155-1162.

Hungate, R. E. 1950. The anaerobic mesophilic cellulolytic bacteria. Bacteriol. Rev. 14:1-49.

Itabashi, H., T. Kobayashi, and M. Matsumoto. 1984. The effects of rumen ciliate protozoa on energy metabolism and some constituents in rumen fluid and blood plasma of goats. Jpn. J. Zootech. Sci. 55:248-255.

Joblin, K. N. 1981. Bacterial and protozoal interactions with ruminal fungi. Pages 311-324 in Microbial and Plant Opportunities to Improve Lignocellulose Utilization by Ruminants. D. E. Akin, L. G. Ljungdahl, J. R. Wilson, and P. J. Harris, ed. Elsevier, New York, NY.

Jouany, J. P., B. Zainab, J. Senaud, C. A. Groliere, J. Grain, and P. Trivend. 1981. Role of the rumen ciliate protozoa Polyplastron multivesiculatum, Entodinium spp. and Isotricha prostoma in the digestion of a mixed diet in sheep. Reprod. Nutr. Dev. 21:871-884.

Kamra, D. N., A. K. Patra, P. N. Chatterjee, R. Kumar, N. Agarwal and L. C. Chaudhary. 2008. Effect of plant extracts on methanogenesis and microbial profile of the rumen of buffalo: A brief overview. Aust. J. Exp. Agric. 48:175-178.

Kim, J. R., S. H. Yeon, H. S. Kim, and Y. J. Ahn. 2002. Larvicidal activity against Plutella xylostella of cordycepin from the fruiting body of Cordyceps militaris. Pest Manag. Sci. 58:713-717.

Kobayashi, Y. 2010. Abatement of methane production from ruminants: Trends in the manipulation of rumen fermentation. Asianaustralas. J. Anim. Sci. 23:410-416.

Koike, S., and Y. Kobayashi. 2001. Development and use of competitive PCR assays for the rumen cellulolytic bacteria: Fibrobacter succinogenes, Ruminococcus albus and Ruminococcus flavefaciens. FEMS Microbiol. Lett. 204:361-366.

Lee, H. G. 2006. Composition for cultivating Cordyceps and cultivating process using thereof. AJU International Law \& Patent Group, assignee. Korea Pat. No. 1006442430000.

Leng, R. A. 1991. Improving ruminant production and reducing methane emissions from ruminants by strategic supplementation. EPA/400/1-91/004. US Environmental Protection Agency, Washington, DC.

Li, S. P., P. Li, T. T. Dong, and K. W. Tsim. 2001. Anti-oxidation activity of different types of natural Cordyceps sinensis and cultured Cordyceps mycelia. Phytomedicine 8:207-212.

Lila, Z. A., N. Mohammed, S. Kanda, T. Kamada, and H. Itabashi. 2003. Effect of sarsaponin on ruminal fermentation with particular reference to methane production in vitro. J. Dairy Sci. 86:33303336.

Lu, C. D., and N. A. Jorgensen. 1987. Alfalfa saponins affect site and extent of nutrient digestion in ruminants. J. Nutr. 117:919-927.

Martin, S. A., and J. M. Macy. 1985. Effects of monensin, pyromellitic diimide and 2-bromoethanesulfonic acid on rumen fermentation in vitro. J. Anim. Sci. 60:544-550.

Moss, A. R. 1993. Methane: Global Warming and Production by Animals. Chalcombe Publications, Kingston, UK.

Müller, W. E. G., G. Seibert, R. Beyer, H. J. Breter, A. Maidhof, and R. K. Zahn. 1977. Effect of cordycepin on nucleic acid metabolism in L5178Y cells and on nucleic acid-synthesizing enzyme systems. Cancer Res. 37:3824-3833.

Namba, T. 1993. The Encyclopedia of Wakan-Yaku (Traditional Sino-Japanese Medicines) with Color Pictures. Vol. II. Hoikusha, Osaka, Japan.

NRC. 1989. Nutrient Requirements of Dairy Cattle. 6th rev. ed. Natl. Acad. Sci., Washington, DC.

Newbold, C. J., B. Lassalas, and J. P. Jouany. 1995. The importance of methanogens associated with ciliate protozoa in ruminal methane production in vitro. Lett. Appl. Microbiol. 21:230-234.
Ogimoto, K., and S. Imai. 1981. Atlas of Rumen Microbiology. Japan Scientific Societies Press, Tokyo, Japan.

Ørskov, E. R., W. P. Flatt, and P. W. Moe. 1968. Fermentation balance approach to estimated extent of fermentation and efficiency of volatile fatty acid formation in ruminants. J. Dairy Sci. 51:1429-1435.

Ørskov, E. R., and I. McDonald. 1979. The estimation of protein degradability in the rumen from incubation measurements weighted according to rate of passage. J. Agric. Sci. Camb. 92:499-503.

SAS Institute. 2011. SAS/OR ${ }^{\circledR} 9.3$ User's Guide: Mathematical Programming Examples. SAS Institute Inc., Cary, NC.

Skillman, L. C., P. N. Evans, C. Strömpl, and K. N. Joblin. 2006. 16S rDNA directed PCR primers and detection of methanogens in the bovine rumen. Lett. Appl. Microbiol. 42:222-228.

Stumm, C. K., H. J. Gijzen, and G. D. Vogels. 1982. Association of methanogenic bacteria with ovine rumen ciliates. Br. J. Nutr. 47:95-99.

Stumm, C. K., and K. B. Zwart. 1986. Symbiosis of protozoa with hydrogen utilizing methanogens. Microbiol. Sci. 3:100-105.

Sugar, A. M., and R. P. McCaffrey. 1998. Antifungal activity of 30-deoxyadenosine (cordycepin). Antimicrob. Agents Chemother. 42:1424-1427.

Takahashi, J. 2001. Nutritional manipulation of methanogenesis in ruminants. Asian-australas. J. Anim. Sci. 14:131-135.

Takahashi, J., A. S. Chaudhry, R. G. Beneke, Suhubdy, and B. A Young. 1997. Modification of methane emission in sheep by cysteine and a microbial preparation. Sci. Total Environ. 204:117-123.

Tang, W., and G. Eisenbrand. 1992. Chinese Drugs of Plant Origin. Springer, New York, NY.

Tsai, C. H., A. Stern, J. F. Chiou, C. L. Chern, and T. Z. Liu. 2001. Rapid and specific detection of hydroxyl radical using an ultraweak chemiluminescence analyzer and a low-level chemiluminescence emitter: Application to hydroxyl radical-scavenging ability of aqueous extracts of food constituents. J. Agric. Food Chem. 49:2137-2141.

Ushida, K., A. Miyazaki, and R. Kawashima. 1986. Effect of defaunation on ruminal gas and VFA production in vitro. Jpn. J. Zootech. Sci. $57: 71-77$.

Ushida, K., M. Tokura, A. Takenaka, and H. Itabashi. 1997. Ciliate protozoa and ruminal methanogenesis. Pages 209-220 in Rumen Microbes and Digestive Physiology in Ruminants. R. Onodera, H. Itabashi, K. Ushida, H. Yano, and Y. Sasaki, eds. Japan Scientific Societies Press, Tokyo, and S. Karger AG, Basel, Switzerland.

Van Nevel, C. J., and D. I. Demeyer. 1977. Effect of monensin on rumen metabolism in vitro. Appl. Environ. Microbiol. 34:251-257.

Wallace, R. J., N. R. McEwan, F. M. McIntosh, B. Teferedegne, and C. J. Newbold. 2002. Natural products as manipulators of rumen fermentation. Asian-australas. J. Anim. Sci. 15:1458-1468.

Wang, Y., T. A. McAllister, L. J. Yanke, and P. R. Cheeke. 2000. Effect of steroidal saponin from Yucca schidigera extract on ruminal microbes. J. Appl. Microbiol. 88:887-896.

Williams, A. G., and G. S. Coleman. 1991. The Rumen Protozoa. Springer-Verlag, New York, NY.

Yeo, J. M. S. J. Lee, S. M. Lee, S. H. Shin, S. H. Lee, J. K. Ha, W. Y. Kim, and S. S. Lee. 2009. Effects of Cordyceps militaris mycelia on in vitro rumen microbial fermentation. Asian-australas. J. Anim. Sci. 22:201-205.

Yeo, J. M., S. J. Lee, S. H. Shin, S. H. Lee, J. K. Ha, W. Y. Kim, and S. S. Lee. 2011. Effects of Cordyceps militaris mycelia on fibrolytic enzyme activities and microbial populations in vitro. Asian-australas. J. Anim. Sci. 24:364-368.

Yu, Z., and M. Morrison. 2004. Improved extraction of PCR-quality community DNA from digesta and fecal samples. BioTechniques $36: 808-812$.

Yuan, J. S., A. Reed, F. Chen, and C. N. Stewart. 2006. Statistical analysis of real-time PCR data. BMC Bioinformatics 7:85-96.

Zhou, X., C. U. Meyer, P. Schmidtke, and F. Zepp. 2002. Effect of cordycepin on interleukin-10M production peripheral blood mononuclear cells. Eur. J. Pharmacol. 453:309-317. 
Zhou, Z., Q. Meng, and Z. Yu. 2011. Effects of methanogenic inhibitors on methane production and abundances of methanogens and cellulolytic bacteria in in vitro ruminal cultures. Appl. Environ. Microbiol. 77:2634-2639.

Zhu, J. S., G. M. Halpern, and K. Johns. 1998a. The scientific rediscovery of an ancient Chinese herbal medicine: Cordyceps sinensis: part I. J. Altern. Complement. Med. 4:289-303.
Zhu, J. S., G. M. Halpern, and K. Johns. 1998b. The scientific rediscovery of a precious ancient Chinese herbal regimen: Cordyceps sinensis: part II. J. Altern. Complement. Med. 4:429-457. 